\title{
The Ecological Integration of Cyber Information Technology and College English Curriculum Network in China
}

\author{
Wang Feifei ${ }^{1, a^{*}}$, Huang Tian- $\mathrm{e}^{2, \mathrm{~b}}$ \\ ${ }^{1}$ Department of English, Hebei University of Economics and Business, Shijiazhuang, 050061, China \\ ${ }^{2}$ Department of English, Hebei University of Economics and Business, Shijiazhuang, 050061, China \\ aemail: wangffei2008@126.com, *corresponding author, bemail: hte0588@163.com
} Keywords: Cyber Information Technology; college English Curricula; Ecological Integration;
Computer Assisted Teaching

\begin{abstract}
With the rapid development of information technology, the nature of college English teaching in China will change fundamentally by the organic integration of English curriculum network and cyber information technology. However, the intervention of cyber information technology is bound to break the original ecological balance in the college English classroom. On such a background, computer assisted teaching has taken a big step forward to the combination of cyber information technology and English curriculum network, but to achieve the goal of ecological integration of the above two aspects, cyber information technology must integrate even deeper into the ecosystem of English curricula, into every aspect of its teaching elements, so that the original one-way linear structure of each teaching element in college English curriculum network is to be broken down internally and a brand new two-way interactive teaching structure which is more efficient is to be rebuilt, in return the ecological balance of college English classroom will be restored ultimately.
\end{abstract}

\section{Introduction}

In the course of college English teaching reform, as a brand new teaching mode, teaching of college English under the influence of cyber information technology has brought unprecedented advantages to the classroom teaching. Meanwhile, it also brings about various impacts and incongruities, so that the ecological balance of traditional college English classroom has been broken, which affected the smooth implementation of the new reform mode of teaching. How to guide efficient integration of teaching and learning resources between cyber information technology and college English curricula, namely, how to give full play to the advantages of information era, how to make the cyber information technology adapt to the needs of the development of modern education and truly integrate into the organic component of the curricula becomes an extremely important issue to promote the transformation of college English teaching from the traditional mode to the modern mode in China, and it has already turned into the research focus of current domestic English teaching reform.

This paper will analyze the status of cyber information technology in the new college English teaching mode and the characteristics of current computer assisted teaching at home from the perspective of ecology and on the base of real teaching practices, and point out that the objective of teaching reform can never be attained when computer is only used as an auxiliary tool, then propose a request that cyber information technology should be fully integrated into the college English curriculum network, so as to achieve the ecological balance of college English curricula in China.

\section{The Cyber Information Technology and Ecological Attributes of College English Curricula}

The cyber information technology can be divided into a broad sense and a narrow sense, and its narrow sense which refers to the collection, the storage, processing, dissemination and application of information, is closely related to foreign language teaching. The cyber information technology used in the field of education is one aspect of the modern information technology with computers as 
the core, namely a modern educational information technology which is able to produce, store, process and convert text, image, voice and digital information, and it has its unique characteristics of digitalization, multimedia, networking and intelligence. Digitalization makes the information conversion and transmission based on high speed operation universal, so that the storage of information is increased, the transmission speed is accelerated, and the quality of transmission is stable and undistorted. The collection, storage, processing and transmission of information implement signal conversion and transmission via high-speed calculating operation, thus convert to multimedia, greatly changing the form of information diversity. Multimedia technology puts many forms of media into integration, such as text, audio, video, photography and so on, and fully mobilizes students' five human senses of hearing, seeing, tasting, smelling and touching, greatly improving students' learning efficiency. The cyber information technology makes information cover widely by transcending the boundary of the time and the space, makes it much more convenient to share resources in the interaction and the cooperation, makes learners easily access to authentic context and rich original corpus, and makes it becomes to the reality for college English learning with more of independence and interaction. Intelligence means that computer can stimulate anthropomorphic thinking. It is able to provide people with a variety of sophisticated information services by making teaching personalized, environment virtualized, management in automation, and information processing intelligent.

With the structural and functional characteristics of an ecosystem, college English classroom is no less than a micro-ecosystem. First of all, of all the general characteristics of all the curricula, college English curriculum is an entirety composed by teachers, students, teaching environment, and other elements. Each internal component of the entirety has its own functions, and an even more powerful whole is constituted via interdependence and interaction among all the components and between components and the whole. Secondly, it has the characteristics of energy flow in the ecosystem. In the classroom ecology, there are teachers, students and classroom teaching environment. Energy flows among these components. Teachers and students in the classroom ecosystem are the energy source of the system. Energy generates and flows through the activities of teaching and learning and teachers and students are not only the producers, consumers and also the decomposers of the ecosystem. Thirdly, the relationship among the ecological factors will grow to be stable or relatively stable, eventually into a state of relative equilibrium, when there is no external intervention for the classroom ecology for quite some time. As a result of the involvement of cyber information technology, the relative balance of college English classroom is broken, while the functions and traits of teachers, students and teaching environment and their roles and power relations will be redistributed, and have an impact on the overall ecology of the college English curricula.

\section{Computer Assisted Teaching and Ecological Imbalance of the College English Curricula}

The application of computer in foreign language teaching began in the late 1970s and gained a rapid development at the end of 1980s in China. Up till now, computer assisted teaching still remains the mainstream state in the English teaching practices in most of the domestic colleges and universities. Computer assisted foreign language teaching can put into involvement of information technology such as computer technology, embedded terminal technology, multimedia technology and network communication technology into all teaching elements, optimize the teaching process and teaching resources, create diversified modes of teaching management and teaching evaluation, and enhance foreign language teaching effects. Although the introduction of cyber information technology has brought a new opportunity and had a significant impact on the contents and forms of the college English teaching in China, it will lead to the inevitable situation of ecological imbalance and highlight various internal contradictions hidden in the traditional college English classroom as well. If computer is regarded just as an assistant tool of teaching, it will be really difficult to achieve the expected goal of teaching reform, and solve the following two major urgent problems as to alleviate the shortage of teaching resources and facilitate the low level of English application for students.

In most cases, teachers often use cyber information technology to demonstrate the teaching 
objectives and difficult or important teaching contents in the form of slide show by courseware to students. The information technology merely plays a supplementary role in the ways of teaching methods and teaching means, and computer assisted teaching seems like another way of transformation to instill various kinds of knowledge into students' minds. As a matter of fact, the role of computer is more like a tool of presentation to assist teachers with teaching focus or difficult teaching problems, so the contents of computer assisted teaching are still based on the textbooks, and the traditional teaching structure of setting teachers as the center and students as the object to be instilled knowledge has not been altered fundamentally. Under such circumstances, computer, as a sort of technology, can only play a supporting role to enhance the teaching effects, but can never become the tool used to solve practical problems in reality [1]. Furthermore, computer has not been taken as an indispensable organic component of college English teaching process, so that the network can not be made effective use of and the sea of teaching resources can not be shared by teachers and students either in the computer assisted teaching practices, not mentioning to reach the goal of making full use of teaching resources. Computer assisted teaching is not able to employ the magnificent and unprecedented technological development of computer technology to create an ideal environment for foreign language teaching and learning by underlining its auxiliary function.

\section{A New Model of Ecological Integration of Cyber Information Technology and the College English Curricula}

In the classroom ecosystem, from the ecological perspective, the teacher is the main but not the only producer of information or knowledge within the system. On the contrary, the student is mainly a learner, and a consumer or a decomposer of information and knowledge. However, in some cases, some students can change their roles or status into the producers within the system to provide information and knowledge and perform the duties of a teacher in a certain sense. Meanwhile, the teacher is no longer a simple producer either, he or she also makes himself or herself as a consumer or a decomposer, to a certain extent, absorbing desirable information and knowledge from the students, the colleagues or even the environment. Thus, both the teacher and the student have three functional identities as the producer, the consumer and the decomposer in the modern classroom ecology, with the identity division of primary one and secondary one for either side, however, as is mentioned above, the teacher is mainly a producer, and the student is mainly a consumer, even though they are able to change their identity from time to time. The teacher, the student and the environment may interact with one another through classroom activities to implement and achieve the natural and necessary flow of different kinds of energy and information.

After the integration of cyber information technology and the college English curricula, the computer has already become an integral part of the entire curriculum system, rather than an optional auxiliary tool. The three major kinds of technologies as artificial intelligence, digital media and networking make possible the integration of this new teaching model, for artificial intelligence is able to simulate anthropomorphic thinking, digital media is able to make an accurate, massive storage of information and networking is able to make computer cover and share with every user a wide range of cyber resources. These three technologies are not only independent, but also interdependent with one another, jointly promoting the amazing functional development of computer technology. So it is natural to create an ideal teaching environment and pattern with the superb technical supports of cyber information technology.

With a rapid development of computer technology, computer has been fully involved in almost all aspects of humans' social life, and it can be said that humans and computers have become an inseparable whole in more than one field. There is no exception for foreign language teaching which can never be separated from computer any more, thus a large number of new terms have been emerging in education, such as e-education, e-learning and e-teaching. Similarly, in the field of foreign language learning, language learners and computers can be regarded as a whole as well, thus from the perspective of ecology, when the above mentioned close relationship happens between language learners and computers, the computer should be taken as an important ecological chain of the ecological system in the field of foreign language learning. On the contrary, it should 
not be excluded from the ecosystem as a cold lifeless object.

Meanwhile, with the development of information technology, multimedia and cyber technology has provided a large number of advanced teaching methods for the foreign language teaching, which has many an advantage incomparable to the traditional teaching methods, and personalizes the teaching methods and diversifies the teaching measures. In this way, foreign language teachers are able to put diversified teaching methods, such as situation creation, conversation or discussion, active exploration, meaning construction and collaborative learning into application. And the multimedia technology has the advantages of integration, interactivity and diversity. It is able to combine the text, the graphs, and the sounds into a whole, mobilize students' various senses by a variety of stimuli, provide a lot of vivid language materials from more than one angle, and present a real environment of language and culture, so that it makes the situational learning possible. Teaching resources are distributed in a structure of diversified, multi-level network, which makes it easy for students to select from and use according to their actual situations, so as to achieve the goal of independent learning. At the same time, students are able to carry out the exploratory learning through the search, the research, and the construction of language meaning in the process of interaction with the computer, so as to cultivate their language skills in the simulation of language environment.

Thanks to the rapid progress of computer and cyber information technology, it makes possible the ecological integration of cyber information technology and college English curricula. After such an effective integration of the new teaching model, the nature of the college English curricula is able to be changed fundamentally. As for the teaching elements of the teacher, the student, the computer and the teaching contents, their relations are not linear one-way any more, but an interactive two-way of interrelation, interdependence and mutual transformation as can be seen in figure 1 below. In the new mode of the ecological integration of cyber information technology and college English curricula, the role of the teacher has changed fundamentally already. They are no longer the center of classroom teaching. The role of the student has changed radically as well. They are not the passive knowledge recipients, but active constructors of knowledge, and the scope of their knowledge sources is also in an expanding way. In addition to the traditional textbooks, learning courseware, television and radio programs, magazines and newspapers, and audio and video products, the students can also absorb massive information and knowledge from the database, software libraries, educational websites, online classroom, the virtual library and other brand new learning channels. Teachers don't have to be confined in the classroom teaching. For with the help of cyber information technology and media technology, teachers are even able to store their teaching materials and teaching contents into the online classroom or high quality course website to carry out much more diversified teaching activities, and as for students, they are able to learn all the teaching contents repeatedly at any moment when they are convenient, at any places where they feel comfortable, only if there are a computer and accessory network available, and they are able to download any useful information from the online classroom or educational websites or even have a discussion with or give feedbacks to their teachers or classmates.

Such an ecological integration of cyber information technology and college English curricula is really a good news for college English students. Although it has already put into usage in some colleges and universities in China, but it still needs some time to make it spread. And cyber information technology will surely plays an even bigger role in the aspects of teaching methods, teaching means, teaching contents and teaching environment of the college English teaching process. Only by doing so, cyber information technology can be truly integrated with the college English curriculum network, so as to achieve the ecological balance of college English curricula in China.

\section{Conclusion}

Based on the ecological point of view, if the cyber information technology intends to be integrated into the ecosystem of the college English curricula in a deep way, it is bound to be integrated into each teaching element of the college English curricula first of all, and endeavors to construct a 
compatible, consistent and balanced relationship with each component of the ecosystem, namely to construct or constitute a microcosmic ecological system. The introduction of cyber information technology into college English teaching has broken the ecological balance of the college English curriculum network. If the teaching elements can not find suitable niche in the ecological system of college English curricula, the phenomena of exclusion, contradiction and imbalance among the various ecological niches will be emerging. As far as the current teaching situation is concerned, most colleges and universities in China still implement the traditional teacher-centered computer assisted teaching. It is a must to have a comprehensive integration of the cyber information technology and the college English curricula, so that the reform on foreign language teaching can be carried out effectively. After the integration, the college English curricula can make a good use of the continuous development of computer and cyber information technology to create an ideal environment for foreign language teaching, so as to change the existing teaching structure fundamentally. Only in this way, all kinds of problems in computer assisted language teaching can be resolved completely, and the ecological system of college English curriculum network can remain in a dynamic balance.

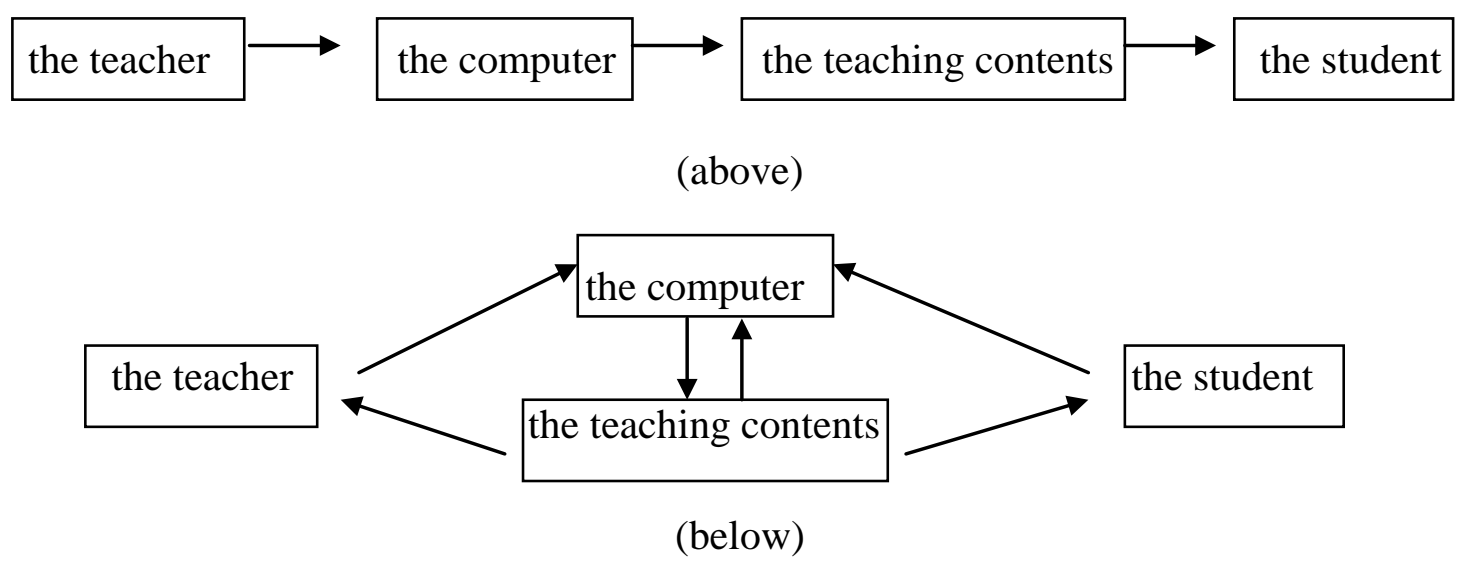

Fig. 1 the linear one-way (above) and the interactive two-way (below) among the teaching elements

\section{References}

[1] Morrison, G. R and Lowther, D. L. Integrating Computer Technology into the Classroom [M]. Pearson Education Asia Limited, 2005.

[2] Brooks, J. G. and Brooks, M. G. In Search of Understanding: The Case for Constructivist Classrooms [C]. Alexandria, VA: Association for Supervision and Curriculum Development, 1993.

[3] Brown, J. S., Collins, A. and Duguid, P. Situated cognition and the culture of learning [J]. Educational Researcher, 1989, 18: 32 - 42.

[4] Stern, H. H. Fundamental Concepts of Language Teaching [M]. Oxford: Oxford University Press, 1983.

[5] Chen Jian-lin. On the Integration of Computer and Internet into Foreign Language Teaching Program [J]. CAFLE, 2006112 (12) 3-10.

[6] Shao Hong-Wan. IT and Foreign Language Education: from Assistance to Normalization in View of a Disciplinary Integration [J]. CAFLE, 2012148 (11) 34-40. 